\title{
Indicators of Formalized Description Quality and Analysis of Production Technologies
}

\author{
Dmitry Andreev \\ Institute of Engineering Sciences \\ Pskov State University \\ Pskov, Russia \\ dandreev60@mail.ru \\ Sergey Verteshev \\ Institute of Engineering Sciences \\ Pskov State University \\ Pskov, Russia \\ verteshev@mail.ru
}

\author{
Alexander Dementiev \\ Institute of Engineering Sciences \\ Pskov State University \\ Pskov, Russia \\ damix01@yandex.ru \\ Olga Timofeeva \\ Institute of Engineering Sciences \\ Pskov State University \\ Pskov, Russia \\ olgant_2103@mail.ru
}

\author{
Sergey Lyokhin \\ Institute of Engineering Sciences \\ Pskov State University \\ Pskov, Russia \\ slyokhin@gmail.com
}

\begin{abstract}
This paper discusses conceptual basis for assessment and analysis of model quality relating to formalized description of technologies. The authors give indicators used to assess formalized and textual descriptions of technologies. They raise some questions concerning the analysis of technologies that enable to make a list of indicators. The paper examines decomposition structures of specific technologies and provides the calculations of introduced coefficients.
\end{abstract}

Keywords - coefficient, concept, decomposition structure, technology.

\section{INTRODUCTION}

The conceptual basis for evaluating and analyzing the quality of models is a very relevant task. The main research directions of this scientific problem are considered in this paper [1]. With regard to the issues raised on the quality assessment of formalized descriptions of production technologies (hereinafter referred to as technologies), constructed in accordance with the fundamental principles of the developed method $[2,3]$, and the development of technology characteristics based on their structural organization, it seems logical to talk about using the basics of structural and topological analysis [4]. Nevertheless, it worth mentioning that present structural and topological characteristics of systems obtained by analyzing traditional topological structures [5] are not suitable for obtaining the results of the above-mentioned actions. This circumstance, first of all, is caused by the impossibility of their practical application to solve the identified issues due to the existing features of the topological organization of the formed decomposition structures of technologies (DST) [6]. In this regard, we propose our own set of indicators of formalized description quality and analysis of technologies, obtained on the basis of studying the topology of the obtained ontological representations [7], which is quite consistent with the general approaches implemented in this field [8] - [10].

\section{DETERMINING A SET OF INDICATORS}

To assess the quality of the formalized description of technologies in comparison with their alternative textual descriptions, two indicators are introduced (when considering them, we take into account only fully formed concepts [11]):

$$
\text { A) } K_{a}=\frac{k_{T D_{\text {formalize }}}}{k_{T D_{\text {textual }}}} \text {, }
$$

where $K_{a}$ - the coefficient of the content

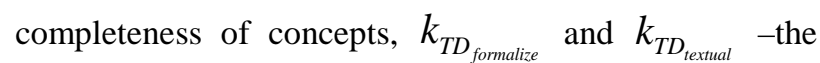
number of concepts of the formalized and textual descriptions of the technology, respectively;

$$
\text { B) } K_{b}=\frac{k_{P_{\text {formalize }}}+k_{F_{\text {formalize }}}}{k_{P_{\text {textual }}}+k_{F_{\text {textual }}}} \text {, }
$$


where $K_{b}$ - the coefficient of the explicit relation of concepts, $k_{P_{\text {formalize }}}$ and $k_{F_{\text {formalize }}}$ - the number of intralevel and inter-level relations between the concepts of the formalized description of technology, respectively, $k_{P_{\text {textual }}}$ и $k_{F_{\text {textual }}}$ - the number of intra-level and interlevel relations between the concepts of the textual description of technology, correspondingly.

For $K_{a}$ in formula (1), the content completeness of concepts is understood as the fact of their complete formation according to definition 2, formulated on the basis of the proposed model [2].

For $K_{b}$ in formula (2), the explicit relation of concepts is understood to mean that they have both intralevel relations of immediate precedence by definition 3 , in accordance with the fulfillment of the theoretical propositions 1-3, and inter-level relations («part-whole») by definition 7 , in accordance with the implementation of the theoretical proposition 4 [2].

The proposed method of formalized description of technologies [2] allows us to raise and solve a number of issues related to the analysis of the technologies under consideration, related to the determination of the following list of indicators (when considering them, we consider only fully formed concepts [11]). Let`s focus on each in a more detailed way.

1) The degree of participation of all DST concepts in the formation of the main technology implementation route reflects the coefficient of non-branching technology:

$$
K_{1}=\frac{k_{d_{\text {formalize }}^{*}}}{k_{d_{\text {formalize }}}},
$$

where $K_{1}$ - the coefficient of non-branching technology, $k_{d_{\text {formalize }}^{*}}$ and $k_{d_{\text {formalize }}}$ - the number of concepts taking part in the formation of the main technology implementation route and all DST concepts, respectively.

The non-branching of the technology is understood as the determination of the maximum depth of the DST, which is identified with obtaining the main route for the implementation of the technology.

2) The degree of participation of all DST concepts in the formation of the longest decomposition level among all unified decomposition constructions (UDC) DST shows the concentration coefficient of the technology:

$$
K_{2}=\frac{k_{s_{\text {formalize }}^{*}}}{k_{s_{\text {formalize }}}},
$$

where $K_{2}$ - the concentration coefficient of the technology, $k_{s_{\text {formalize }}^{*}}$ and $k_{s_{\text {formalize }}}$ - the number of concepts presenting decomposition level of the most massive UDC and all the DST concepts respectively.
The concentration of the technology is understood as determining the maximum width of the decomposition level among all UDC DST, which is identified with obtaining the length of the decomposition level of the most massive UDC DST.

3) The degree of distribution of all DST concepts by the holistic UDC concepts reflects the coefficient of grouping technology:

$$
K_{3}=\frac{k_{t_{\text {formalize }}^{*}}}{k_{t_{\text {formalize }}}},
$$

where $K_{3}$ - the coefficient of grouping technology, $k_{t_{\text {formalize }}^{*}}$ and $k_{t_{\text {formalize }}}$ - the number of concepts located in the apexes of UDC and all DST concepts correspondingly.

The grouping of the technology is understood as determining the common number of decomposition levels of all UDC DST.

4) The share of DST concepts fulfilling the implementation of the technology with the help of the equipment (machines, tools, etc.) shows the mechanization coefficient of the technology:

$$
K_{4}=\frac{k_{T D_{\text {formalize }}^{W}}}{k_{T D_{\text {formalize }}}},
$$

where $K_{4}$ - the mechanization coefficient of the technology, $k_{T D_{\text {formalize }}^{W}}$ and $k_{T D_{\text {formalize }}}$ - the number of concepts where equipment is used and all the DST concepts respectively.

The mechanization of the technology is understood as its implementation by means of different kinds of equipment.

5) The share of DST concepts that ensure the correct implementation of the technology by introducing thirdparty inclusions from outside reflects the coefficient of third-party inclusions of the technology:

$$
K_{5}=\frac{k_{T D_{\text {formalize }}^{X}}}{k_{T D_{\text {formalize }}}},
$$

where $K_{5}$ - the coefficient of third-party inclusions of the technology, $k_{T D_{\text {formalize }}^{X}}$ and $k_{T D_{\text {formalize }}}$ - the number of concepts which demand the implementation of the third-party inclusions and all the DST concepts respectively.

The third-party inclusions of the technology are understood as material components, without the use of which it is impossible to ensure the correct implementation of the technology.

\section{THE RANGE OF TECHNOLOGIES UNDER CONSIDERATION}

According to the text of the introduction of this article, the object of research is technologies focused on material production. The implementation of modern technologies 
is impossible either without specific industrial enterprises (plants, factories, etc.), each having a specific industry orientation, and production laboratories, or without the participation of qualified labor. In this paper, we consider technologies in the form of standardized textual descriptions that do not contain language contradictions and semantic omissions [12, 13]. These descriptions take into account the compatibility factor of the material components [14] involved in determining the concepts of technological actions. The most widespread in material production are those areas that are characterized by the following features, both in terms of the specifics of the description and in terms of the conditions for the implementation of specific technologies [2]:

- the representation of the possible cyclicity of individual technological actions can be considered in the form of a corresponding technological chain of concepts of technological actions;
- the output of any of the technological actions can only be input to one other technological action within the decomposition levels;

- if there is a cumulative input for a certain technological action, its formation will take place in accordance with the scheme of logical AND [15];

- numerical values of the corresponding cost characteristics of the concepts of technological actions located in the nodes of the DST have the property of additivity.

Numerous technologies fully meet these assumptions. Among them are the technologies of clothing production [16], a significant part of construction technologies [17] and mechanical engineering technologies [18]. As concrete examples, this article discusses the technological sequences of mechanical processing a part of the «Screw» type (Fig. 1, left) [19], the construction of a brick residential house (Fig. 1, right) [20], the making of men's trousers (Fig. 2), men's coat (Fig. 3) and men's jacket (Fig. 4) $[21]-[24]$.
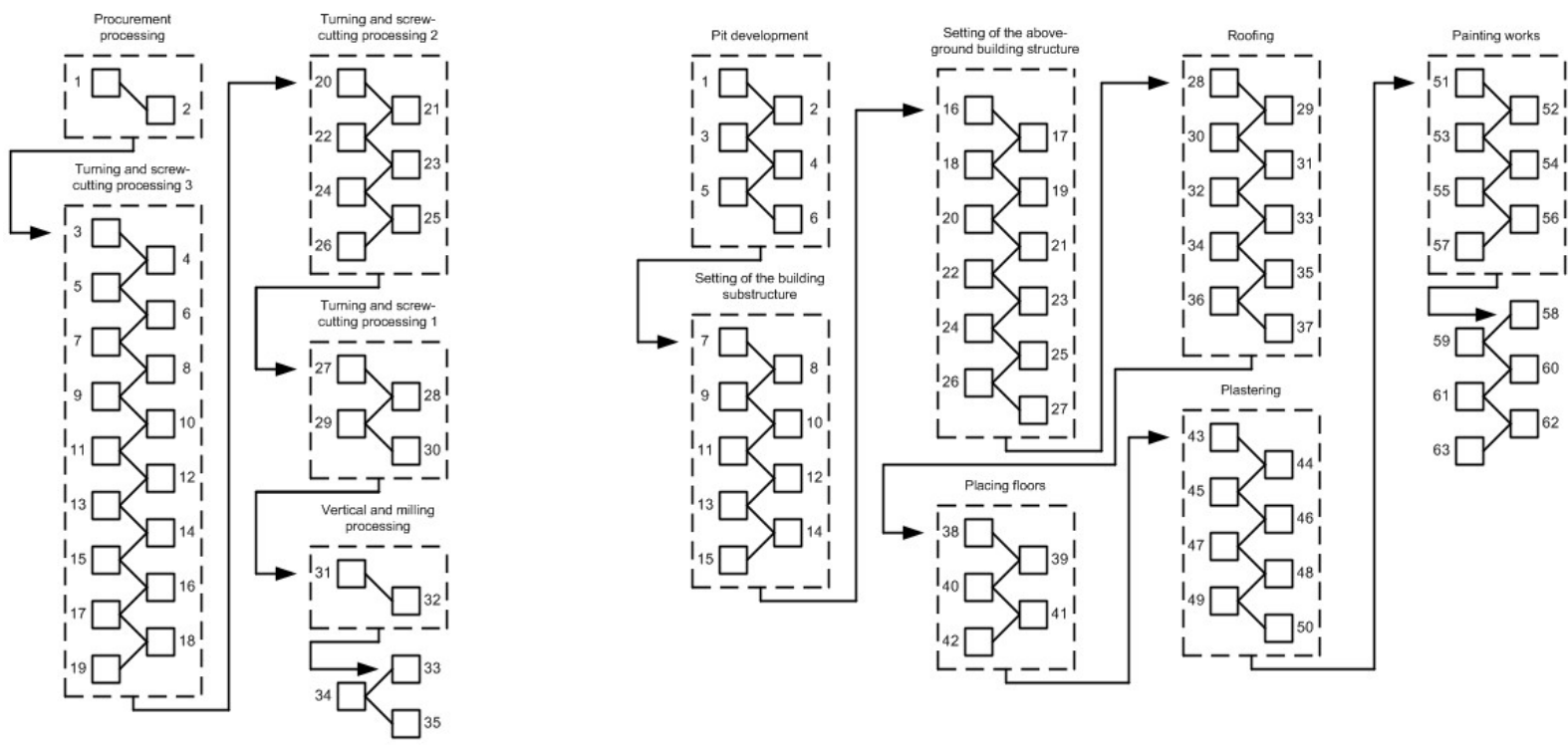

FIG. 1. TECHNOLOGICAL SEQUENCE OF MECHANICAL PROCESSING A PART OF THE «SCREW» TYPE (LEFT) AND TECHNOLOGICAL SEQUENCE OF A BRICK RESIDENTIAL HOUSE CONSTRUCTION (RIGHT). 
Dmitry Andreev et al. Indicators of Formalized Description Quality and Analysis of Production Technologies

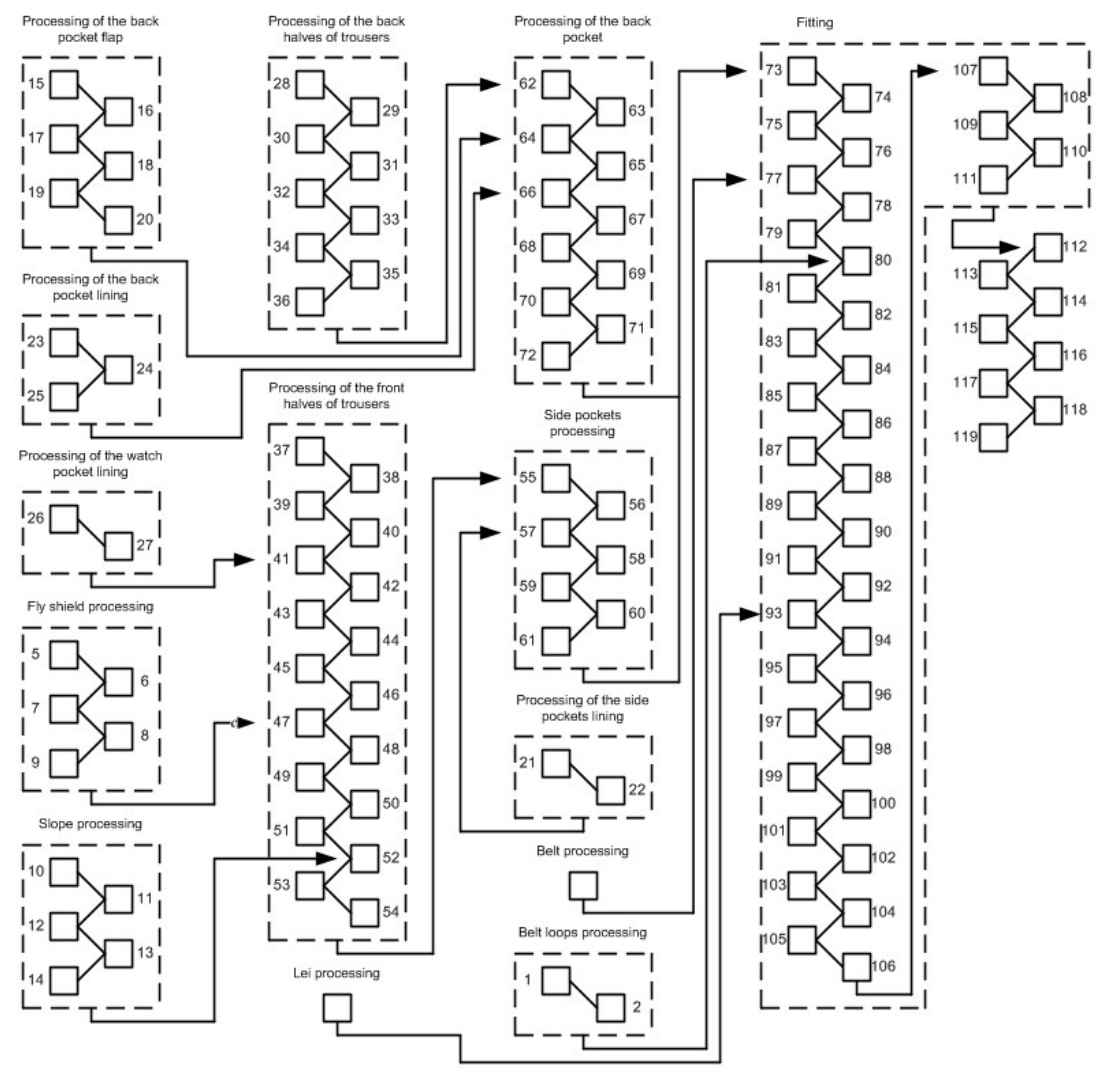

FIG. 2. TECHNOLOGICAL SEQUENCE OF MEN`S TROUSERS MAKING

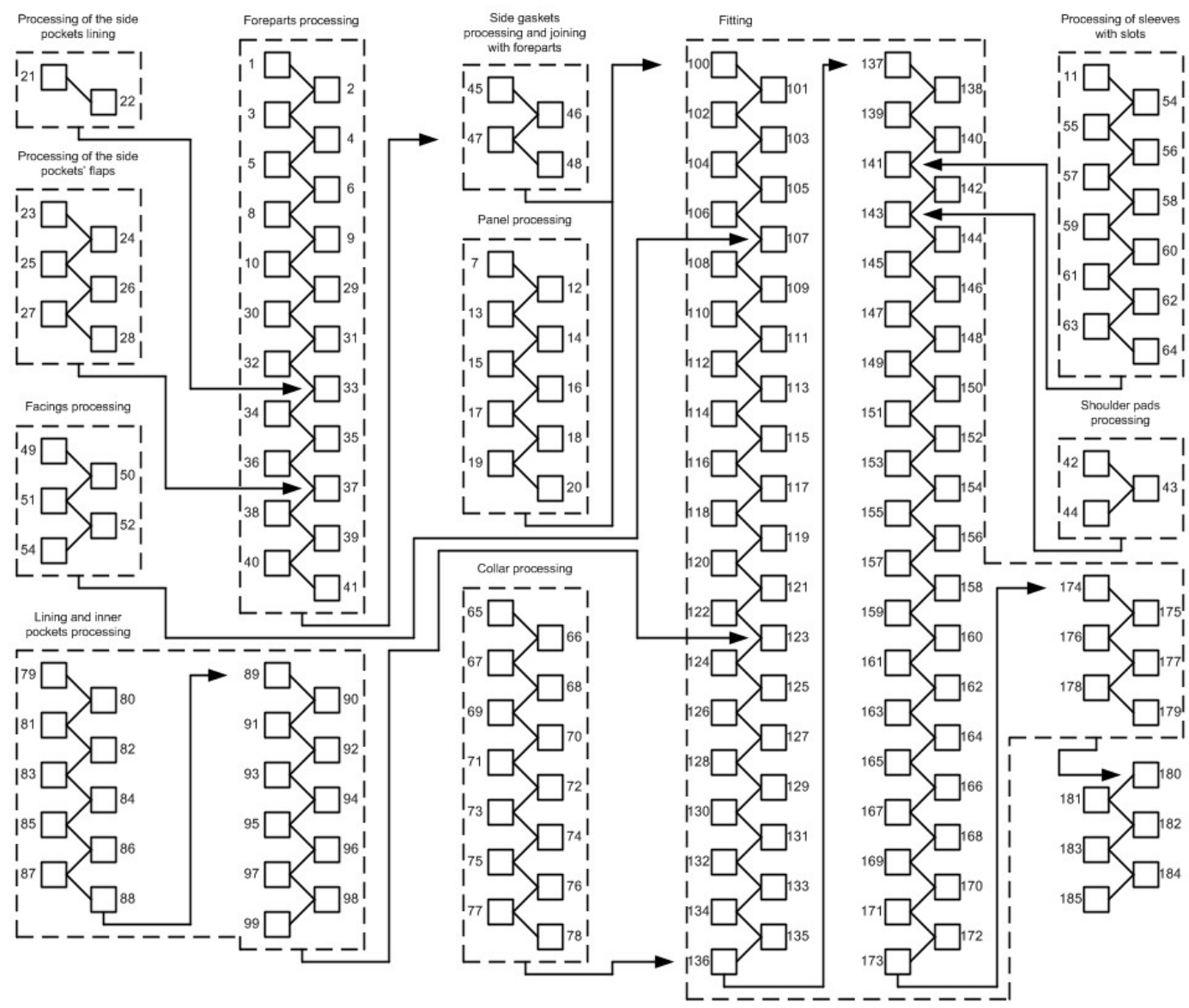

Fig. 3. TECHNOLOGICAL SEQUENCE OF MEN`S COAT MAKING 


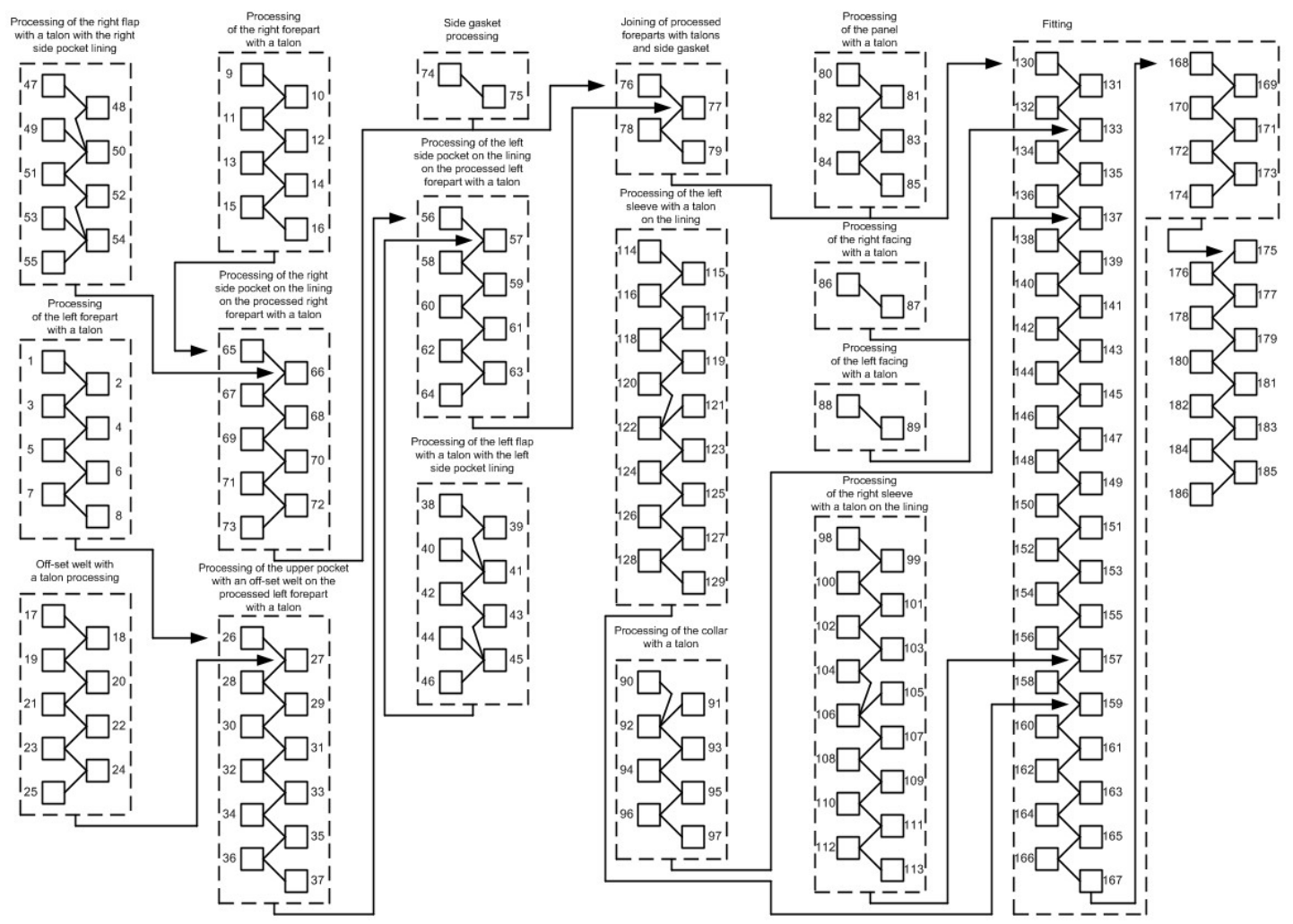

FIG. 4. TECHNOLOGICAL SEQUENCE OF MEN'S JACKET MAKING

\section{Quantitative Calculations of THE COEFFICIENTS INTRODUCED}

According to the analytical descriptions of all these indicators, which are presented in paragraph II, it is proposed to make their quantitative calculation for all the technologies under consideration. We are talking about the technology of making a men's jacket (TMM jacket), the technology of making a men's coat (TMM coat), the technology of making men's trousers (TMM trousers), the technology of construction a brick residential house (TCBR house) and the technology of mechanical processing a part of the «Screw» type (TMPP «Screw»).

First, we present the quantitative calculation results of indicators of formalized description quality of technologies.

A) Determination of the coefficient of the content completeness of concepts:

- For TMM jacket $K_{a}=\frac{204}{186}=1,097$;

- For TMM coat $K_{a}=\frac{197}{185}=1,065$;

- For TMM trousers $K_{a}=\frac{132}{119}=1,109$;

- For TCBR house $K_{a}=\frac{71}{63}=1,127$;
- For TMPP «Screw» $K_{a}=\frac{41}{35}=1,171$.

B) Determination of the coefficient of the explicit relation of concepts

- For TMM jacket

$$
K_{b}=\frac{184+203}{167+0}=\frac{387}{167}=2,317 ;
$$

- For TMM coat

$$
K_{b}=\frac{181+196}{170+0}=\frac{377}{170}=2,218 ;
$$

- For TMM trousers

$$
K_{b}=\frac{117+131}{105+0}=\frac{248}{105}=2,362 ;
$$

- For TCBR house

$$
K_{b}=\frac{62+70}{55+0}=\frac{132}{55}=2,4 ;
$$

- For TMPP «Screw»

$$
K_{b}=\frac{34+40}{29+0}=\frac{74}{29}=2,552 .
$$

The obtained values of the coefficients $K_{a}$ and $K_{b}$ for the technologies under consideration also indicate the advantage of formalized descriptions of technologies over their alternative textual descriptions: in terms of the 
indicator $K_{a}-$ from $6.5 \%$ to $17.1 \%$, and in terms of the indicator $K_{b}$ - more than twice.

Let's consider the results of the quantitative calculation of the technologies analysis indicators.

1) Determination of the non-branching coefficient

- For TMM jacket $K_{1}=\frac{104}{204}=0,51$;

- For TMM coat $K_{1}=\frac{123}{197}=0,624$;

- For TMM trousers $K_{1}=\frac{84}{132}=0,636$;

- For TCBR house $K_{1}=\frac{71}{71}=1$;

- For TMPP «Screw» $K_{1}=\frac{41}{41}=1$.

Therefore, the more DST concepts are involved in the formation of the main technology implementation route the closer indicator $K_{1}$ is to the singular.

2) Determination of the concentration coefficient;

- For TMM jacket $K_{2}=\frac{52}{204}=0,255$;

- For TMM coat $K_{2}=\frac{87}{197}=0,442$;

- For TMM trousers $K_{2}=\frac{44}{132}=0,333$;

- For TCBR house $K_{2}=\frac{13}{71}=0,183$;

- For TMPP «Screw» $K_{2}=\frac{18}{41}=0,439$.

Turns out that the more DST concepts are involved in the formation of the longest decomposition level among all DST UDC, the closer the indicator $K_{2}$ is to a singular.

3) Determination of the grouping coefficient:

- For TMM jacket $K_{3}=\frac{18}{204}=0,088$;

- For TMM coat $K_{3}=\frac{12}{197}=0,06$;

- For TMM trousers $K_{3}=\frac{13}{132}=0,098$;

- For TCBR house $K_{3}=\frac{8}{71}=0,113$;

- For TMPP «Screw» $K_{3}=\frac{6}{41}=0,146$.
Thus, the less DST concepts are distributed among the holistic concepts of the UDC DST, the closer the indicator $K_{3}$ is to 0.5 .

4) Determination of the mechanization coefficient:

- For TMM jacket $K_{4}=\frac{148}{204}=0,725$;

- For TMM coat $K_{4}=\frac{129}{197}=0,655$;

- For TMM trousers $K_{4}=\frac{96}{132}=0,727$;

- For TCBR house $K_{4}=\frac{27}{71}=0,38$;

- For TMPP «Screw» $K_{4}=\frac{41}{41}=1$.

Turns out that the more DST concepts ensure the technology implementation via equipment, the closer indicator $K_{4}$ is to the singular.

5) Determination of third-party inclusions coefficient:

- For TMM jacket $K_{5}=\frac{58}{204}=0,284$;

- For TMM coat $K_{5}=\frac{58}{197}=0,294$;

- For TMM trousers $K_{5}=\frac{41}{132}=0,311$;

- For TCBR house $K_{5}=\frac{65}{71}=0,915$;

- For TMPP «Screw» $K_{5}=\frac{7}{41}=0,171$.

Therefore, the more DST concepts ensure correct implementation of the technology via third-party inclusions, the closer indicator $K_{5}$ is to a singular.

Based on the results of the calculations made, it is possible to present a summary table of all values indicators (Table I), through which the analysis of the technologies under consideration is carried out.

TABLE 1 CALCULATED VALUES OF TECHNOLOGIES ANALYSIS INDICATORS

\begin{tabular}{|c|c|c|c|c|c|}
\hline \multirow{2}{*}{ Technology name } & \multicolumn{5}{|c|}{ Calculated indicator } \\
\cline { 2 - 6 } & $K_{1}$ & $K_{2}$ & $K_{3}$ & $K_{4}$ & $K_{5}$ \\
\hline TMM jacket & 0,51 & 0,255 & 0,088 & 0,725 & 0,284 \\
\hline TMM coat & 0,624 & 0,442 & 0,06 & 0,655 & 0,294 \\
\hline TMM trousers & 0,636 & 0,333 & 0,098 & 0,727 & 0,311 \\
\hline TCBR house & 1 & 0,183 & 0,113 & 0,38 & 0,915 \\
\hline TMPP «Screw» & 1 & 0,439 & 0,146 & 1 & 0,171 \\
\hline
\end{tabular}

V. CONCLUSION

This paper considers indicators of formalized description quality and analysis of technologies with the results of the corresponding calculations, which differ 
from the existing indicators by their determination and calculation, based on the topological organization features of the DST formed.

Determining the indicators of content completeness and explicit relation of concepts allows us to assess the quality of the formalized description of technologies under consideration in quantitative terms. Based on the results of other calculations, a summary table of the values of the indicators is presented, through which the analysis of the selected technologies has already been carried out.

Thus, the formalized description of technologies under consideration fully meets the proposed quality criteria in the form of content completeness and explicit relation of concepts in comparison with their alternative textual descriptions, and previously developed models and algorithms [2] contribute to the effective analysis of technologies.

\section{REFERENCES}

[1] B. V. Sokolov and R. M. Yusupov, "Conceptual foundations for evaluating and analyzing the quality of models and polymodel complexes," Izvestiya RAS. Theory and Control Systems, No. 6, pp. 5-16, 2004. (in Russian)

[2] D. Andreev, S. Lyokhin, L. Motaylenko, and S. Verteshev, "Models and algorithms for constructing a formalized description of production technologies," in Environment. Technology. Resources: Proceedings of the 12th International Scientific and Practical Conference on Information Technologies, Rezekne, 2019, vol. II, pp. 21-27.

[3] D. Andreev, S. Lyokhin, V. Nikolaev, and O. Poletaeva, "Development of software for design ontological representations of production technologies," in Environment. Technology. Resources: Proceedings of the 12th International Scientific and Practical Conference on Information Technologies, Rezekne, 2019, vol. II, pp. 28-33.

[4] V. I. Pozhbelko, "Method of topological structural analysis and new criteria for identification of complex multi-contour mechanical systems,” Theory of Mechanisms and Machines, Vol. 12, No. 2 (24), pp. 50-65, 2014. (in Russian)

[5] Programming and operating systems, "Structural and topological characteristics of systems,” 2015. [Online]. Available: http://vscode.ru/articles/struct-topolog-charact-system.html [Accessed: Feb. 25, 2021]. (in Russian)

[6] D. A. Andreev and M. V. Voronov, "Features of ontological engineering of technological knowledge," in proceedings of the XVI All-Russian joint conference on the Internet and Modern Society, Saint-Petersburg, 2013, pp. 74-76. (in Russian)

[7] D. A. Andreev and M. V. Voronov, "On the specifics of the ontological representation of material production technologies," in abstracts of the IX international conference on mathematical modeling in education, science and production, Tiraspol, 2015, p. 5-6. (in Russian)

[8] T. A. Gavrilova, V. A. Gorovoy, and E. S. Bolotnikova, "Evaluation of the cognitive ergonomics of ontology based on graph analysis,” Artificial Intelligence and Decision Making, No. 3, pp. 33-41, 2009. (in Russian)
[9] O. F. Andrich and L. A. Makushkina, "Research of methods for assessing the quality of ready-made ontological models," Modern Scientific Research and Innovation, No. 3, 2014. [Online serial]. Available: http://web.snauka.ru/issues/2014/03/31194 [Accessed: Feb. 25, 2021]. (in Russian)

[10] L. A. Makushkina and A. A. Rybanov, "Evaluation of the quality of structuring educational material based on metrics of ontological models," Izvestiya of Volgograd State Technical University, Vol. 11, No. 14 (141), pp. 86-89, 2014. (in Russian)

[11] D. A. Andreev, "Model of actions' concepts in ontological representations of technologies," in proceedings of the XXVII international scientific conference on mathematical methods in engineering and technologies, Tambov, 2014, vol. 3, pp. 85-87. (in Russian)

[12] S. Verteshev, V. Konevtsov, "Processes control with fuzzy initial information in a complex of software design of digital control systems," in Environment. Technology. Resources: Proceedings of the 11th International Scientific and Practical Conference on Engineering sciences and production technologies, Rezekne, 2017, vol. III, pp. 332-336.

[13] S. Verteshev, V. Konevtsov, "Direct digital control in a complex of software design of digital control systems," in Environment. Technology. Resources: Proceedings of the 11th International Scientific and Practical Conference on Engineering sciences and production technologies, Rezekne, 2017, vol. III, pp. 337-342.

[14] I. Antonov, I. Bruttan, D. Andreev, and L. Motaylenko, "The method of automated building of domain ontology," in Environment. Technology. Resources: Proceedings of the 12th International Scientific and Practical Conference on Information Technologies, Rezekne, 2019, vol. II, pp. 34-37.

[15] V. Konevtsov, I. Poletaev, S. Verteshev, "Discrete automatic schemes for ASC TP,” in Environment. Technology. Resources: Proceedings of the 10th International Scientific and Practical Conference on Engineering sciences and production technologies, Rezekne, 2015, vol. I, pp. 67-71.

[16] L. F. Pershina and S. V. Petrova, Technology of sewing production. Moscow: KDU, 2007. (in Russian)

[17] A. S. Statsenko, Technology of construction production. Russian Rostov-on-Don: Phoenix, 2006. (in Russian)

[18] B. M. Bazrov, Fundamentals of mechanical engineering technology. Moscow: Mashinostroenie, 2005. (in Russian)

[19] S. K. Sysoev, A. S. Sysoev, and V. A. Levko, Technology of mechanical engineering. Design of technological processes. Saint Petersburg: Lan, 2011. (in Russian)

[20] Construction of a brick 5-storey 70-apartment residential building of series 114-87-1/1, Vpttransstroy (All-Union Design and Technology Institute of Transport Construction), 1980. (in Russian)

[21] P. P. Koketkin, T. N. Kochegura, and V. I. Baryshnikova, Industrial technology of clothing. Moscow: Book on Demand, 2012. (in Russian)

[22] A. T. Trukhanova, Production of men's outerwear for individual orders. Moscow: Legprombytizdat (Light industry and consumer services), 1990. (in Russian)

[23] State Standard (GOST) 25295-2003. Clothing upper coat and suit assortment. General Technical Conditions, Standartinform, 2006. (in Russian)

[24] N. M. Volkova and S. V. Petrova, Production of men's and children's costumes. Moscow: Legprombytizdat (Light industry and consumer services), 1985. (in Russian) 